\title{
Low Salinity Water and Foam Flooding in Sandstone Reservoirs Bearing Heavy Oil
}

\author{
Hasan N. Al-Saedi a, b, c \\ a Al-Amarah University College, Amarah, Missan 62001, Iraq \\ ${ }^{b}$ Iraqi Ministry of Oil, Missan Oil Company, Amarah, Missan 62001, Iraq \\ ${ }^{c}$ Missouri S and T: Missouri University of Science and Technology, Rolla, MO, USA 65401 \\ hnav36@umsystem.edu
}

\begin{abstract}
This study investigates foam and water flooding (especially low salinity (LS) water flooding). Generally, injecting LS water alters sandstone wettability towards being more water-wet, is an effective EOR technique that improves oil recovery. Foams were also employed to enhance oil recovery due to its ability to increase residual oil mobility and sweep efficiency. Combining both LS water and foam into a novel attempt that takes advantage of the relative strengths of both EOR methods. This EOR combination was tested on Berea sandstone cores saturated with heavy oil. The ultimate outcome from this work is a "recipe" of EOR methods in combination, which utilizes LS water and foam to achieve recovery of over 72.65 percent of OOIP in core flooding tests. The core-flooding results showed that an increased heavy oil recovery was obtained by injecting foam and lowering water salinity. The contact angle and interfacial tension (IFT) measurements agreed with the core-flooding results.
\end{abstract}

\section{Introduction}

Nowadays, improving heavy oil recovery draw oil industry attentions. The remaining trapped original oil in place in the oil reservoirs is $70 \%$, which mean only $30 \%$ of the OOIP 
has already been extracted (Kamranfar and Jamialahmadi, 2014). Many factors cause vast amounts of oil to be trapped in oil reservoirs such as energy depletion, heterogeneity, residual oil, high oil viscosity, fractures, and oil wet reservoir rock. In order to extract more oil, solutions must be applied to overcome the previously mentioned problems, such as secondary and tertiary oil recovery. Many enhanced oil recovery methods (EOR) have been proposed in the literature. These EOR processes could be chemical, thermal, and gas injection. Recently, waterflooding has drawn attention as an emerging EOR process that could increase oil recovery. Low salinity (LS) water is another form of waterflooding used to enhance oil recovery by modifying the injected water compositions. Low salinity (LS) water has been extensively studied in the literature in attempts to significantly increase oil recovery (Tang and Morrow, 1999; Austad et al., 2010; Austad, 2013; Awolayo et al., 2018; Nasralla et al., 2014; Al-Saedi et al., 2019a, 2019b). The LS water flooding controlling function seems to be wettability alteration through modification of oil and mineral surface interactions (Al-Saedi and Flori et al., 2018d, 2018e, 2018f). Wettability of an oil/brine/sandstone system is a significant factor that governs residual oil saturation. Wettability of rock is defined as the tendency of one fluid to spread on the rock surface when other fluid(s) is present (Craig, 1971).

Foams, on the other hand, has been employed to enhance oil recovery. Foams can be defined as a mixture of gas, surfactant, and water separated by lamellae (Schramm, 2010). Foam is usually used to improve the sweep efficiency and mobility control of the injected fluids especially gaseous (Mast, 1972; Guo et al., 2011; Denney et al., 2013; Ocampo et al., 2013; Dugstad et al., 2011).

Foams is also used in naturally fractured reservoirs (Chevallier et al., 2018) and in multi- 
layered systems (Lee and Kam, 2015). A field trial using foam as a gas injection conformance enhancer has been conducted by Ocampo et al. (2013) resulting in a 50\% incremental oil recovery with a noticeable decrease in the gas oil ratio (GOR). Another foam field project was implemented in the Snorre field (Svorstol et al., 1996; Skauge et al., 2002).

LS water is an EOR method that can be combined with different EOR processes such as polymer (Ayirala et al., 2010), $\mathrm{CO}_{2}$ (Cuong et al., 2014), surfactant (Khanamiri et al., 2015), and steam (Al-Saedi and Flori et al., 2018d). Combined EOR techniques provides advantages of the combined methods. Coupling both foam and LS water flooding take advantage of the relative strengths of both methods.

\section{Methodology}

\subsection{Materials and Experimental Procedure}

All the cores were flooded initially with two pore volumes (PVs) formation water (FW). FW contains $\mathrm{NaCl}, \mathrm{CaCl}_{2}, \mathrm{MgCl}_{2}$, and $\mathrm{Na}_{2} \mathrm{SO}_{4}$, which together form 104,550 ppm total dissolved salts. The FW pH is 6.94. Four cores were flooded successively with foam and different brine concentrations. Synthetic seawater (SW) used in this study had a salinity of $48,300 \mathrm{ppm}$. SW was diluted with deionized water to produce the other brines. SW was diluted 2 times, 10 times, and 50 times to make $\mathrm{d}_{2 \mathrm{sw}}, \mathrm{d}_{10 \mathrm{sw}}$, and $\mathrm{d}_{50 \mathrm{sw}}$, respectively. Table 1 illustrates the brine compositions. The surfactant solution (SS) was prepared using $1.0 \%$ surfactant concentration in water. The surfactant solution (SS) $\left(\mathrm{CH}_{3}\left(\mathrm{CH}_{2}\right)_{11} \mathrm{SO}_{4}{ }^{-} \mathrm{Na}^{+}\right)$was prepared in water using $1.0 \%$ sodium dodecyl sulfonate (SDS). Colt Energy delivered the crude oil. The crude oil properties are shown in Table 2. The crude oil was centrifuged to remove water and deposits. 
Table 1

Brine Compositions (mM).

\begin{tabular}{lccccc}
\hline Element & FW & SW & $\mathbf{d}_{2 \text { Sw }}$ & $\mathbf{d}_{10 \text { Sw }}$ & $\mathbf{d}_{50 \text { Sw }}$ \\
\hline $\mathrm{NaCl}$ & 13689 & 5133 & 2566.5 & 513.3 & 102.7 \\
$\mathrm{CaCl}_{2}$ & 1802 & 135 & 67.5 & 13.5 & 2.7 \\
$\mathrm{MgCl}_{2}$ & 420 & 1260 & 630 & 126 & 25.2 \\
$\mathrm{Na}_{2} \mathrm{SO}_{4}$ & 39 & 316 & 158 & 31.6 & 6.3 \\
$\mathrm{TDS}$ & 104550 & 48300 & 24150 & 4830 & 966 \\
\hline
\end{tabular}

Table 2

Crude oil properties.

\begin{tabular}{|c|c|c|c|}
\hline Viscosity, cP & Density, gm/cc & TAN, $\mathbf{m g ~ K O H / g}$ & TBN, $\mathbf{~ m ~ K O H / g ~}$ \\
\hline$>600$ & 0.83 & 1.10 & 1.90 \\
\hline
\end{tabular}

Berea sandstone cores were taken from the same block. The XRD shows that they contain 93\% quartz and the rest was kaolinite. All the cores were cut to one inch in diameter. The cores' permeability and porosity were $110 \mathrm{md}$ and $21 \%$ on average, respectively. The cores are identical in petrophysical properties. After the cores were cut, they were dried overnight inside an oven, and the next day they were evacuated and saturated with FW. The weight difference between unsaturated and saturated is used to measure porosity. The core permeability was measured by loading the Berea sandstone core into a Hassler core holder with a confining pressure that did not exceed 600 psi. FW was flooded at different flow rates, and the pressure was recorded. Crude oil was then injected to achieve Swi. The core holder was then cleaned, and the cores were put into a closed container containing heavy crude oil and aged inside an oven at $90^{\circ} \mathrm{C}$. After the initial flood with $\mathrm{FW}$, the core-flooding experiments were performed in a four similar way but with different brines at $45^{\circ} \mathrm{C}$ as shown in Table 3.

To perform the proposed experiments, a core-flooding setup was configured in the 
laboratory as shown in Fig. 1. A syringe pump from Isco was used to inject water into the accumulators that contain different fluids. Multiple valves were installed in between the accumulators to control the injected fluid. A manual confining pump filled with deionized water was used to pump the deionized water into the space above the rubber sleeve that contains the Berea sandstone in order to imitate the overburden pressure, which was set to be 600 psi higher than the injection pressure. A Hassler core holder was used with pressure transducers installed on both sides of the core holder to monitor the pressure drop across the Berea sandstone. A backpressure regulator was connected at the core holder outlet, and graduated tube was used to collect the produced fluids. All the equipment was installed inside a Despatch oven (except the pumps), which was set to $45^{\circ} \mathrm{C}$.

Table 3

Tertiary core-flooding procedure.

\begin{tabular}{|c|c|c|c|c|}
\hline $\begin{array}{l}\text { Plug } \\
\text { name }\end{array}$ & Core-flooding procedure & Brine type & Pore Volume & Brine salinity \\
\hline A11 & $\mathrm{FW}+\mathrm{SW}$ & SW & 15.77 & 48300 \\
\hline A12 & $F W+d_{2 s W}$ & $d_{2 s w}$ & 15.23 & 24150 \\
\hline A13 & $F W+d_{10 s w}$ & $\mathrm{~d}_{10 \mathrm{sw}}$ & 16 & 4830 \\
\hline A14 & $\mathrm{FW}+\mathrm{d}_{50 \mathrm{sW}}$ & $d_{50 s w}$ & 15.91 & 966 \\
\hline \multicolumn{5}{|c|}{3 Cycles } \\
\hline B31 & $\begin{array}{c}\mathrm{FW}+0.5 \mathrm{PV} \mathrm{SS}+0.5 \mathrm{PV} \mathrm{CO}_{2}+ \\
0.5 \mathrm{PV} \mathrm{SW}\end{array}$ & SW & 16.1 & 48300 \\
\hline B35 & $\begin{array}{c}\mathrm{FW}+0.5 \mathrm{PV} \mathrm{SS}+0.5 \mathrm{PV} \mathrm{CO}_{2}+ \\
0.5 \mathrm{PV} \mathrm{d}_{2 s W} \\
\end{array}$ & $d_{2 s w}$ & 16 & 24150 \\
\hline B45 & $\begin{array}{c}\mathrm{FW}+0.5 \mathrm{PV} S S+0.5 \mathrm{PV} \mathrm{CO}_{2}+ \\
0.5 \mathrm{PV} \mathrm{d}_{10 \mathrm{sW}}\end{array}$ & $\mathrm{d}_{10 \mathrm{sw}}$ & 15.88 & 4830 \\
\hline B47 & $\begin{array}{c}\mathrm{FW}+0.5 \mathrm{PV} \mathrm{SS}+0.5 \mathrm{PV} \mathrm{CO}_{2}+ \\
0.5 \mathrm{PV} \mathrm{d}_{50 \mathrm{sW}}\end{array}$ & $d_{50 s w}$ & 16.24 & 966 \\
\hline $\mathrm{C} 13$ & $\mathrm{FW}+0.5 \mathrm{PV} \mathrm{SS}+0.5 \mathrm{PV} \mathrm{CO}_{2}$ & No Brine & 16.16 & - \\
\hline
\end{tabular}




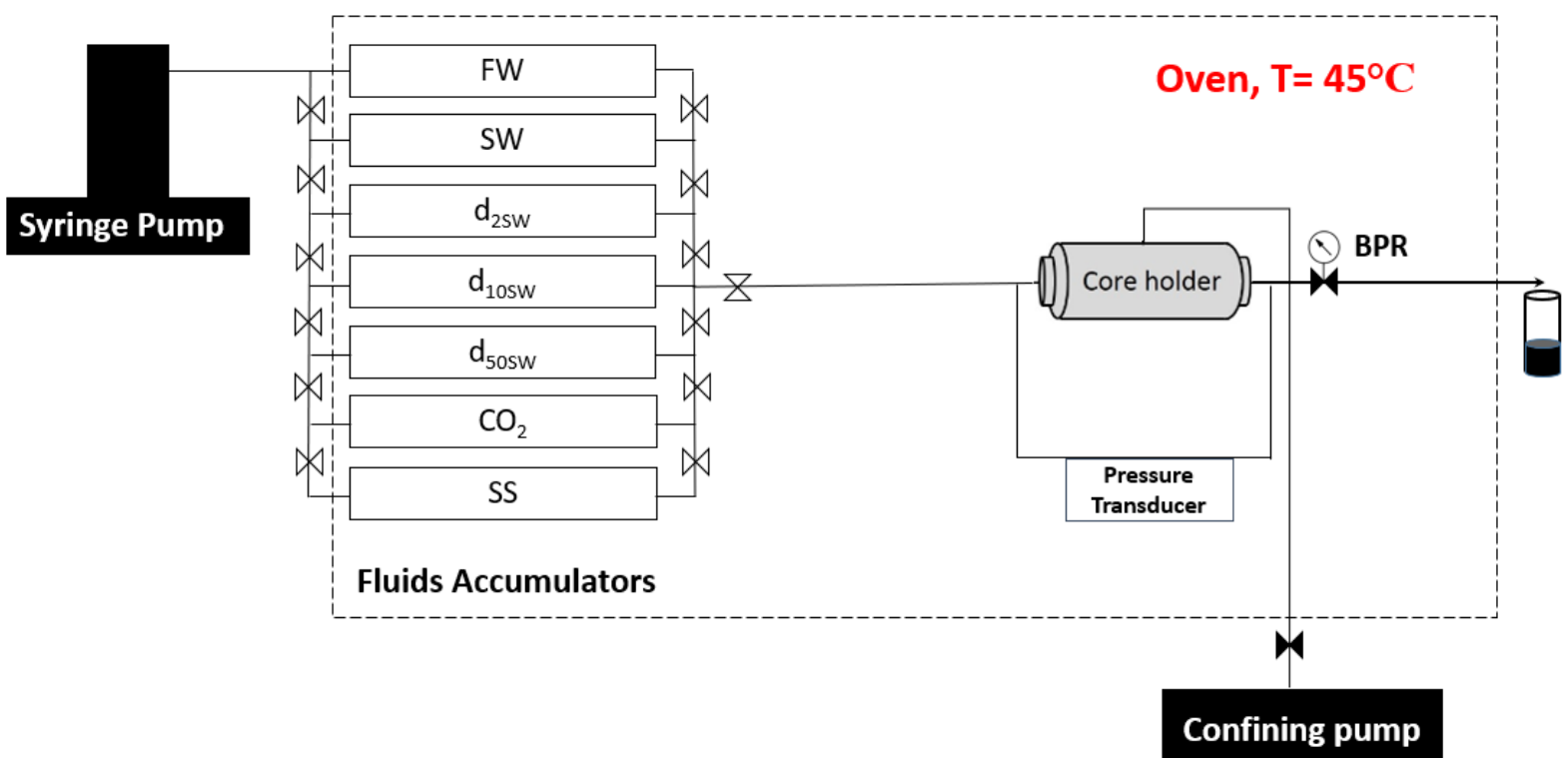

Fig. 1. Schematic of the core flooding apparatus.

\subsection{Contact Angle Measurement Procedure}

The crude oil and Berea sandstone rock contact angle were measured as a wettability indicator. The substrate cut taken from the core plug was saturated with crude oil at $\mathrm{S}_{\mathrm{wi}}$, as explained previously. To obtain a smooth surface, the substrate cut from the Berea sandstone was sanded with sandpaper. The substrates were loaded into the oven to be dried and were then treated with air to remove the minerals' fines. The substrates were then attached to a glass sheet by glue and installed in the test chamber. The desired fluid was then poured into the chamber until the substrate was immersed. The contact angle was then measured after an hour stabilization of the oil droplet on the substrate.

After core-flooding experiments were completed, a substrate cut was then taken from the flooded core for another set of contact angle measurements, which followed the same procedure as previously mentioned. 


\section{Results and Discussion}

\subsection{Water Flooding Experiments}

Before testing the new foam flooding design with different brines, four cores were initially flooded with FW, followed with $\mathrm{SW}, \mathrm{d}_{2} \mathrm{Sw}, \mathrm{d}_{10 \mathrm{SW}}$, and $\mathrm{d}_{50 \mathrm{SW}}$. This was done in order to differentiate with using the same brines with foam and to investigate each brine's effect on improved oil recovery. As expected, the lower brine salinity improved oil recovery. The oil recovery during FW was similar in the four cores. The results of oil recovery were close to each other because the core material and experiment conditions were similar. The oil recovery during $\mathrm{FW}$ flooding was $45.2,44.6,45$, and $45.2 \%$ of the original oil in place (OOIP) for cores A11, A12, A13, and A14, respectively. The additional oil recovery due to injecting $\mathrm{SW}, \mathrm{d}_{2 \mathrm{SW}}, \mathrm{d}_{10 \mathrm{Sw}}$, and $\mathrm{d}_{50 \mathrm{Sw}}$ was $2.3,4.45,5.8$, and $7.8 \%$ of the OOIP, respectively. The water flooding PVs were similar to those in foam experiments to limit result uncertainty. The injected FW PVs were 2 PVs, while it was 4.5 for the tertiary mode

of the other brines. It is worth mentioning that fines migration was observed when injecting both $\mathrm{d}_{10 \mathrm{sw}}$ and $\mathrm{d}_{50 \mathrm{sw}}$. The results of the four water-flood experiments are shown in Fig. 2. 


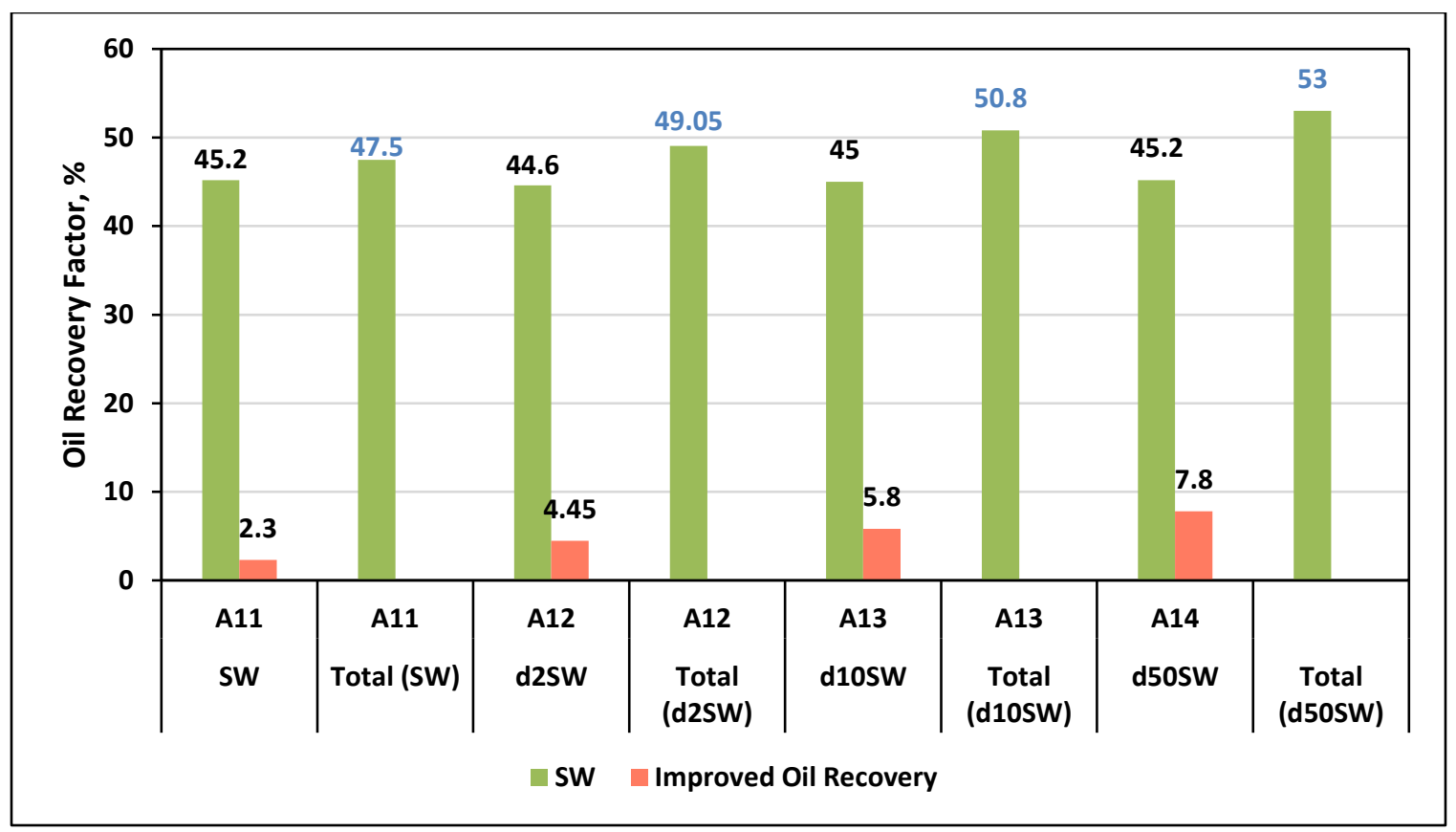

Fig. 2. Core-flooding experiments for the cores flooded with brines only.

\subsection{Foam and water flooding experiments}

In these experiments, the injection patterns were identical as can be seen from Table 3. To investigate the effect of brine salinity on foam flooding, four brines were used in this section: SW (48300 ppm), $\mathrm{d}_{2 \mathrm{SW}}(24150 \mathrm{ppm}), \mathrm{d}_{10 \mathrm{sw}}(4830 \mathrm{ppm})$, and $\mathrm{d}_{50 \mathrm{SW}}(966 \mathrm{ppm})$. After the secondary recovery mode with FW, three cycles of brine and foam were performed. Core B31 was flooded with $2 \mathrm{PVs}$ FW followed with three cycles of $0.5 \mathrm{PV}$ for each injected fluid. The injected fluids were $\mathrm{SS}, \mathrm{CO}_{2}$, and $\mathrm{SW}$. The same design was applied for the other three cores except the brine was different. B35, B45, and B47 were flooded with $\mathrm{d}_{2 \mathrm{sw}}, \mathrm{d}_{10 \mathrm{sw}}$, and $\mathrm{d}_{50 \mathrm{sw}}$ alternatively with foam, respectively. Because the four cores consist of the same materials, the oil recovery during FW flooding for all four cores was about the same.

The oil recovery during the initial $2 \mathrm{PVs}$ FW in core B31 was $45 \%$ of the OOIP. The same oil recovery ( $0.2 \%$ less) was observed in B35, while it was $44.1 \%$ in core B45 and $44.3 \%$ 
in core B47 (Figs. 3-5). The pressure change across the cores was nearly the same with the pressure increasing from $0 \mathrm{psi}$ to 5-6 psi. Similarly, the oil recovery was nearly the same in the first cycle of foam (0.5 PV SS + 0.5 PV CO 2$)$ in all four cores used in this section due to the identical properties of the Berea sandstone core plugs and the conditions applied in all experiments. The oil recovery for the first foam cycle was 6, 6.2, 6.3, 6.16\% OOIP for cores B31, B35, B45, and B47, respectively (Figs. 3-5). After 1 PV of foam was injected, 0.5 PV of SW was injected behind the foam, which provided an additional 3\% OOIP. The total oil recovery from the first cycle was $9 \%$ of the OOIP. The first $1 \mathrm{PV}$ of injected foam extracted 6\% OOIP due to improvement in sweep efficiency compared with water flooding the core bearing heavy oil. The $0.5 \mathrm{PV}$ of SW encountered a free bank of oil released after the foam was injected. However, the first cycle of foam and $\mathrm{d}_{2 \mathrm{sw}}$ flooded into core B35 produced $10.8 \%$ of the OOIP. The lower injected brine salinity provided more oil recovery than SW, which can be ascribed to wettability alteration, as discussed later in the contact angle section. The first cycle of foam and $\mathrm{d}_{10 \mathrm{sw}}$ in the core B45 caused an increase in the tertiary recovery up to $12.45 \%$ of the OOIP, which was higher than the two previous experiments. The $\mathrm{d}_{10 \mathrm{sw}}$ salinity is $4830 \mathrm{ppm}$ (see Table 1). The high oil recovery improvement was due to the wettability alteration towards being more water-wet. The highest oil recovery during the first cycle of foam and brine was when $\mathrm{d}_{50 \mathrm{sw}}$ was injected into core B47. The oil recovery was $14 \%$ of the OOIP, which was the most out of all previous cores. This tremendous result was due to the lower salinity of $d_{50}$ sw. Due to the low PV of injected SS in the first cycle, no oil recovery was observed during SS flooding at the beginning of the first cycle.

During the second cycle of foam and SW, the oil produced only when foam was injected. 
No additional oil recovery was observed during SW flooding, meaning that high saline brine is not a suitable candidate for foam flooding. However, the oil recovery for B31 during the second cycle was $2.7 \%$ of the OOIP, which was entirely done by foam flooding. Diluting SW twice $\left(\mathrm{d}_{2 \mathrm{SW}}\right)$ was not useful in the second cycle of core B35 as in B31 with SW. Diluting SW ten times ( $\left.\mathrm{d}_{10 \mathrm{sw}}\right)$ triggered the B45 core's wettability to be more waterwet and to release more oil out the core (about $1.5 \%$ ) making the total oil recovery from both foam and $\mathrm{d}_{10 \mathrm{sw}}$ around $6.6 \%$ of the OOIP. Interestingly, lowering the injected water salinity to $966 \mathrm{ppm}$ increased oil recovery in the second cycle of the core B47 to $12.5 \%$ of the OOIP, which represents the highest oil recovery in the second cycle in this study. An oil recovery of $12.5 \%$ is a high oil recovery, which was accolmlished by the effect of both foam and LS water flooding.

In the third cycle, no additional oil recovery was obtained in the core B31 due to the effect of the high saline SW at the end of the second cycle. A little oil recovery of $0.75 \%$ was observed in the core B35 for the same reason as mentioned above. The improved oil recovery in the cores B45 and B47 was 1.2 and $1.85 \%$ of the OOIP, respectively. It is obvious that lower injected water salinity triggers the sandstone wettability to become more water-wet, allowing for more oil to be detached from Berea sandstone core plugs. The pressure drop profile behaved the same way in all the cores in this section. The pressure drop increased during SS flooding and decreased dramatically during $\mathrm{CO}_{2}$ flooding due to its low density. It is worth mentioning that fines migration was observed during the flooding of cores B45 and B47 as a result of low salinity water flooding (Tang and Morrow, 1999). This fines migration led to an increase in the pressure in the late first cycle as shown in Fig. 5a, Fig. 5b, Fig. 6a, and Fig. 6b. Fines migration prompted more oil recovery and 
pressure increases due to fines blocking the pore throat of the porous media. The blocked pore throat redirects the fluid to flow in another path, which improves sweep efficiency of the injected fluid and increases the area that was swept thus increasing oil recovery. Fines were also observed by the naked eye in the effluent.

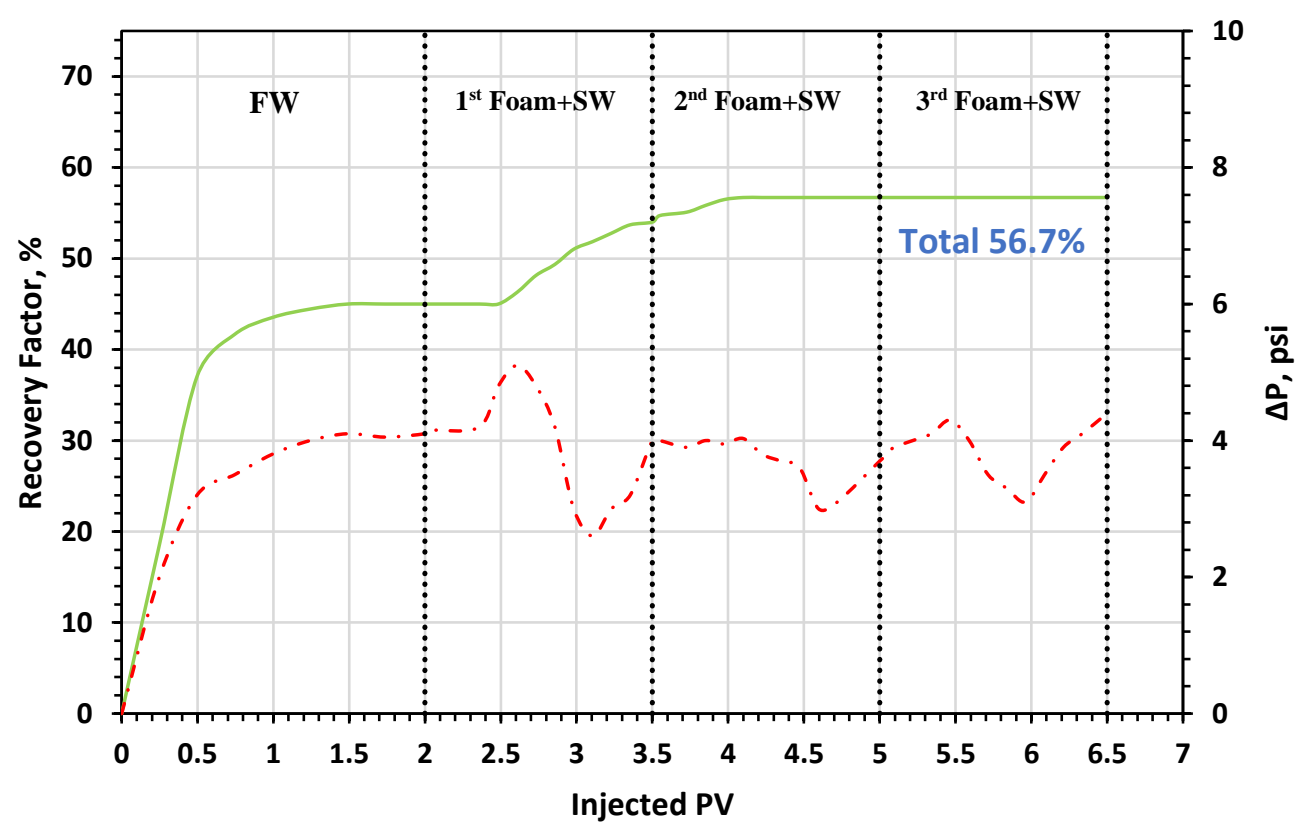

Fig. 3. Oil recovery factor and pressure drop across B31 by injecting $2 \mathrm{PV} F \mathrm{~F}$ and three cycles of foam and SW. 


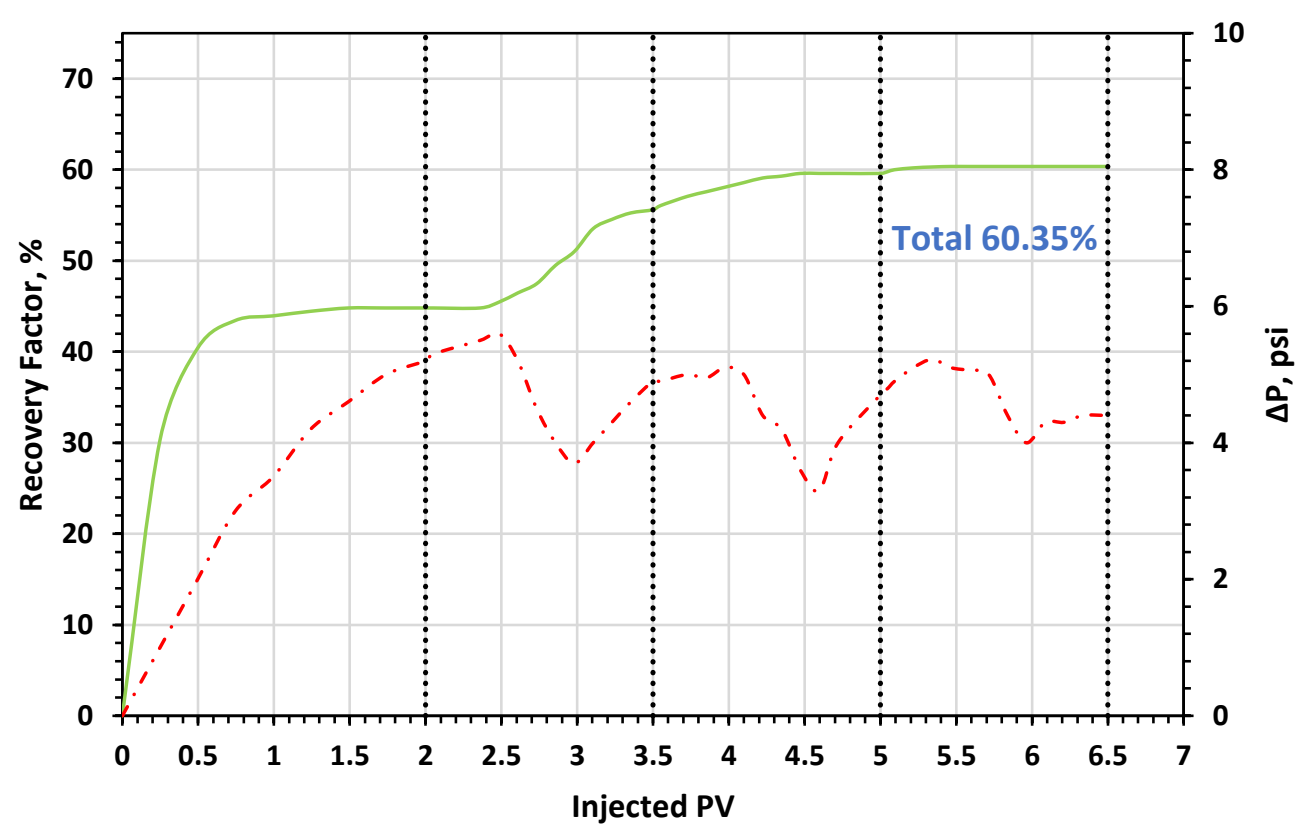

Fig. 4. Oil recovery factor and pressure drop across B35 by injecting 2 PV FW and three cycles of foam and $\mathrm{d}_{2 \mathrm{SW}}$.
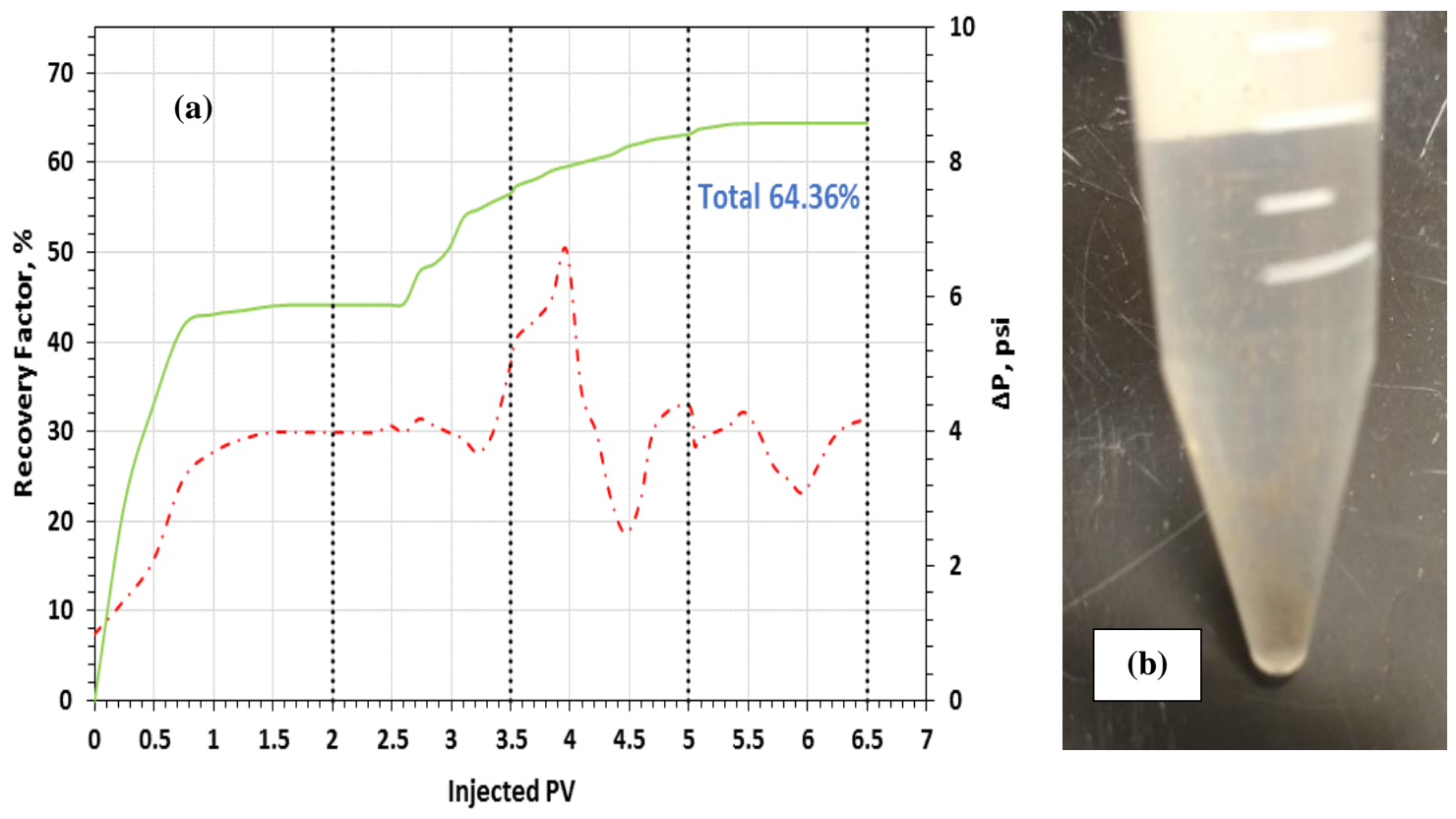

Fig. 5. (a) Oil recovery factor and pressure drop across B45 by injecting 2 PV FW and three cycles of foam and $\mathrm{d}_{10 \mathrm{sw}}(\mathrm{b})$ Fines in the effluent. 

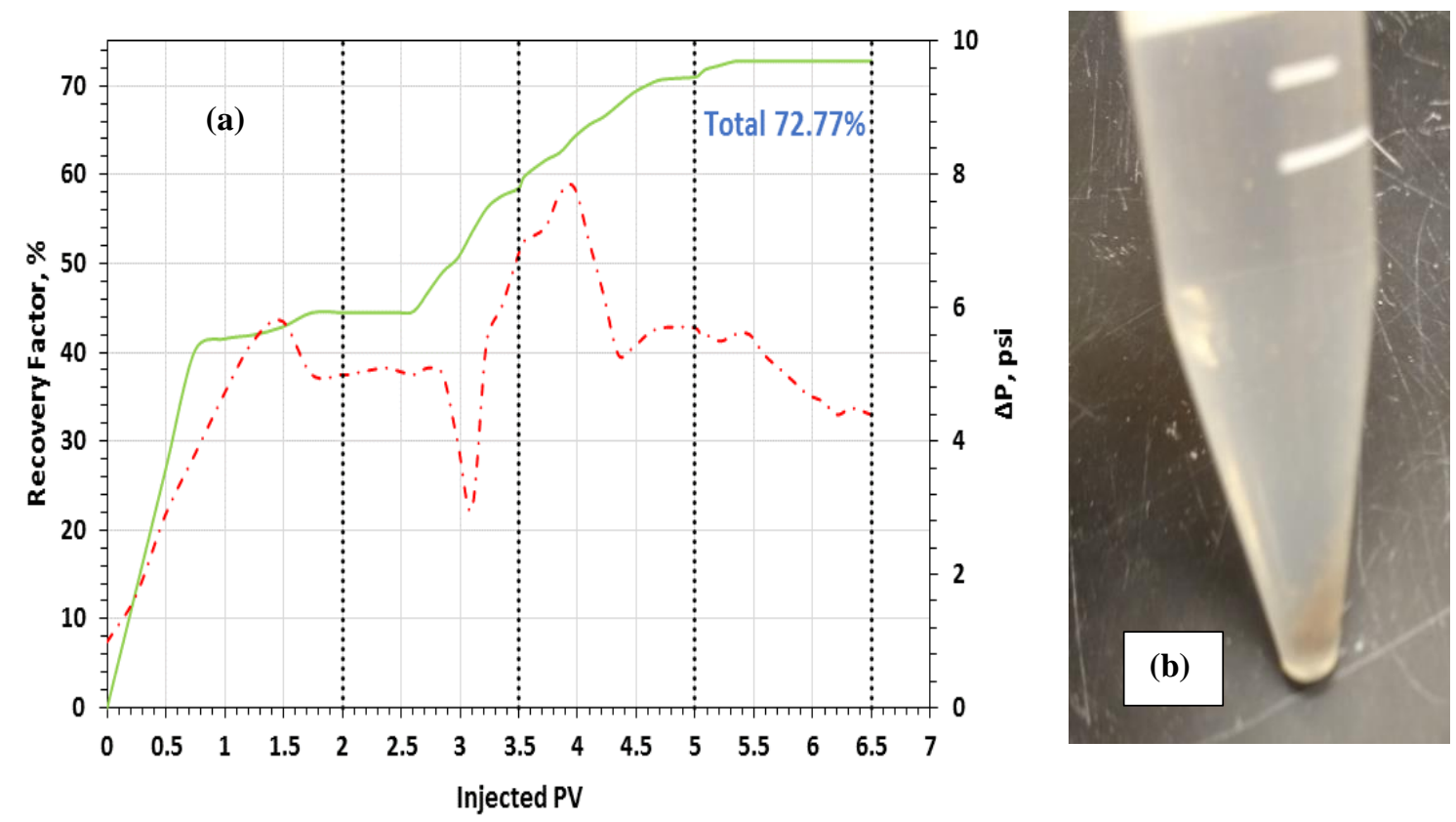

Fig. 6. (a) Oil recovery factor and pressure drop across B47 by injecting 2 PV FW and three cycles of foam and $d_{50 s w}(b)$ Fines in the effluent.

\subsection{Foam flooding}

In the first section of the result and discussion, we conducted water flooding experiments only to identify the significance of the injected brines designed in this study. In this section, core-flooding was performed on a core identical to the all cores used in this study for foam flooding only. This was done to investigate the effect of the injected brined on foam flooding. The oil recovery during the $2 \mathrm{PVs}$ of $\mathrm{FW}$ was similar to the all cores in this study. The oil recovery was $43.85 \%$ of the OOIP. Upon switching to the first foam cycle, the improved oil recovery was $7.8 \%$ of the OOIP, which was lower than the cores B31, B35, B45, and B47. The second cycle recovered $2.15 \%$ of the OOIP, which was again lower than the other cores. No additional oil recovery was observed after injecting the third cycle. The results of this experiment were in line with the expectations. Injection water, even high saline water such as $\mathrm{SW}$, triggers more oil recovery than if the only foam was injected. We 
believe that after the injection of the foam, the free oil released by the foam is not produced entirely. Therefore, injecting water displaces the free oil bank formed by the foam reaction. Furthermore, the injected water associated with foam can change the rock wettability towards water-wet, prompting additional oil to be released from the rock. The results of this experiment can be found in Fig. 7. Table 4 shows the oil recovery results from foam and water flooding and foam only.

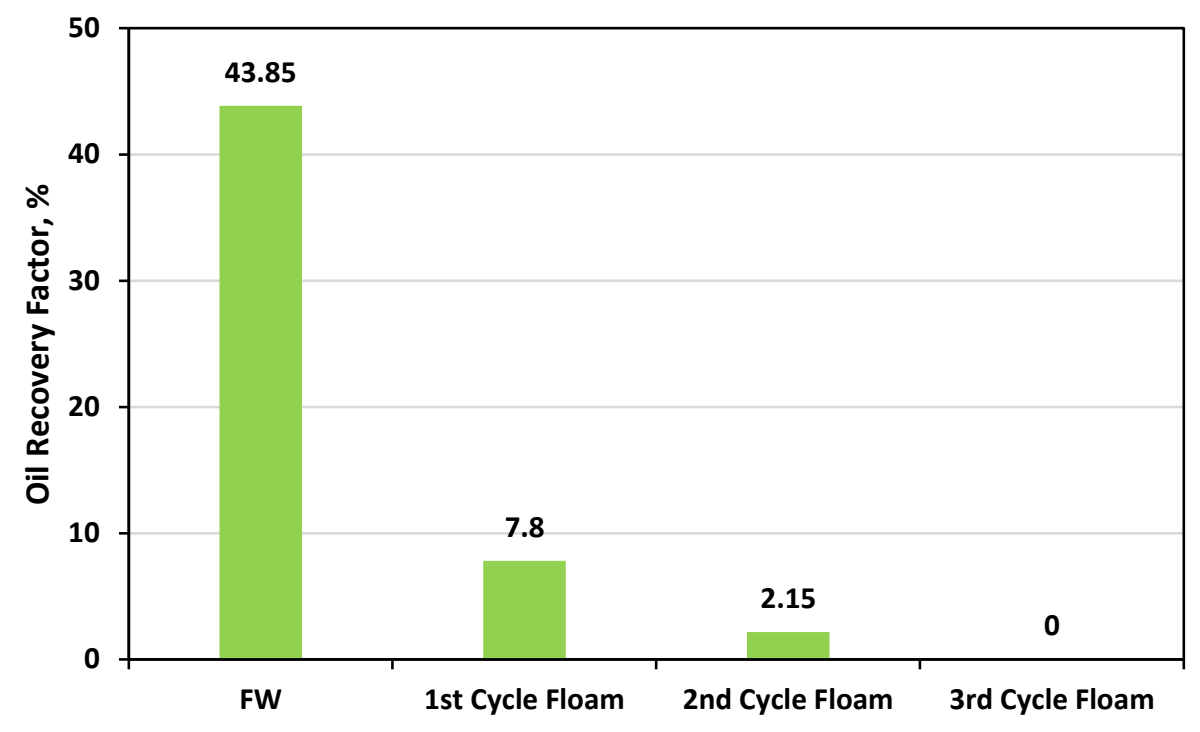

Fig. 7. Core-flooding experiments for the cores flooded with foam only.

\section{Table 4}

Oil recovery data due to foam flooding with and without brine.

\begin{tabular}{|c|c|c|c|c|c|c|c|c|}
\hline $\begin{array}{l}\text { Plug } \\
\text { Name }\end{array}$ & FW & $\begin{array}{c}\text { 1st } \\
\text { Cycle }\end{array}$ & $\begin{array}{c}\text { 2nd } \\
\text { Cycle }\end{array}$ & $\begin{array}{c}\text { 3rd } \\
\text { Cycle }\end{array}$ & Total & Tertiary & $\begin{array}{c}\text { Associated } \\
\text { Brine }\end{array}$ & Remarks \\
\hline B31 & 45 & 9 & 2.7 & 0 & 56.7 & 11.7 & SW & \\
\hline B35 & 44.8 & 10.8 & 4 & 0.75 & 60.35 & 15.55 & $\mathrm{~d}_{2 \mathrm{SW}}$ & \\
\hline B45 & 44.1 & 12.45 & 6.6 & 1.2 & 64.35 & 20.25 & $\mathrm{~d}_{10 \mathrm{SW}}$ & $\begin{array}{l}\text { fines observed which increases } \\
\text { pressure, redirect fluids to new } \\
\text { flow path }\end{array}$ \\
\hline B47 & 44.3 & 14 & 12.5 & 1.85 & 72.77 & 28.35 & $\mathrm{~d}_{50 \mathrm{sw}}$ & $\begin{array}{l}\text { fines observed which increases } \\
\text { pressure, redirect fluids to new } \\
\text { flow path }\end{array}$ \\
\hline $\mathrm{C} 13$ & 43.85 & 7.8 & 2.15 & 0 & 53.8 & 9.95 & No Brine & Foam only \\
\hline
\end{tabular}




\subsection{Contact Angle Results}

To verify the core-flood experiments results, a contact angle test was performed on the substrate cut from the cores before and after flooding. Each core was tested with the desired brine. All the cores were in neutral wettability conditions before flooding (see Fig. 8). After foam-brine flooding was completed, other substrates cut were taken from the flooded cores, and contact angle tests were performed again. The results revealed that as the salinity decreases, the resulting contact angle decreased as well. For core B31, the contact angle was $118^{\circ}$ before flooding the core with three cycles of foam and SW. After flooding, the contact angle dropped to $79^{\circ}$. Foam flooding leads to a decrease in the core wettability towards being near water-wet. For core B35, the contact angle was $111^{\circ}$ before flooding, while after flooding, it was $74^{\circ}$. The contact angle decreased from $101^{\circ}$ to $57^{\circ}$ (water-wet) in core B45.

The biggest change in wettability occurred when using foam and $\mathrm{d}_{50 \text { swin }}$ core $\mathrm{B} 47$. The contact angle results reveal that as the salinity of the injected brine with foam decreases, as the contact angle decreases too, and that explains the higher oil recovery in core B47.

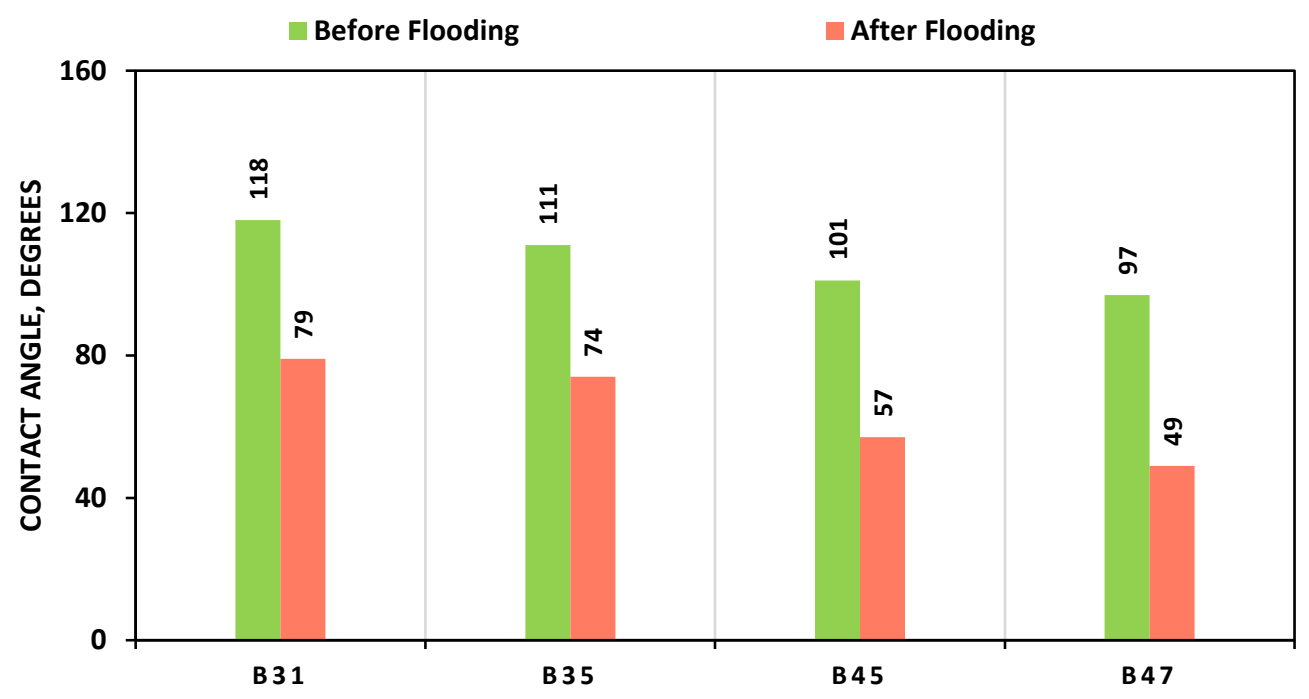

Fig. 8. Contact angle results for Cores B31, B35, B45, and B47. 


\subsection{Interfacial Tension Test (IFT)}

To test the IFT of fluids with crude oil, we conducted this test between oil and the previously mentioned fluids. The interfacial tension between oil and the solutions was determined by the axisymmetric drop shape analysis using the pendant drop method (Ramé-hart advanced goniometer 500-F1). The oil drop (crude oil) was immersed in the surfactant solution by a precise syringe. The interfacial tension between oil and water was measured as soon as the oil droplet was formed. The interfacial tension values were obtained using the Young-Laplace equation. The results of the IFT are shown in Fig. 8. As can be noticed from Fig. 9, as the salinity of the mixed water with foam decreases, the resulting IFT decreased too.

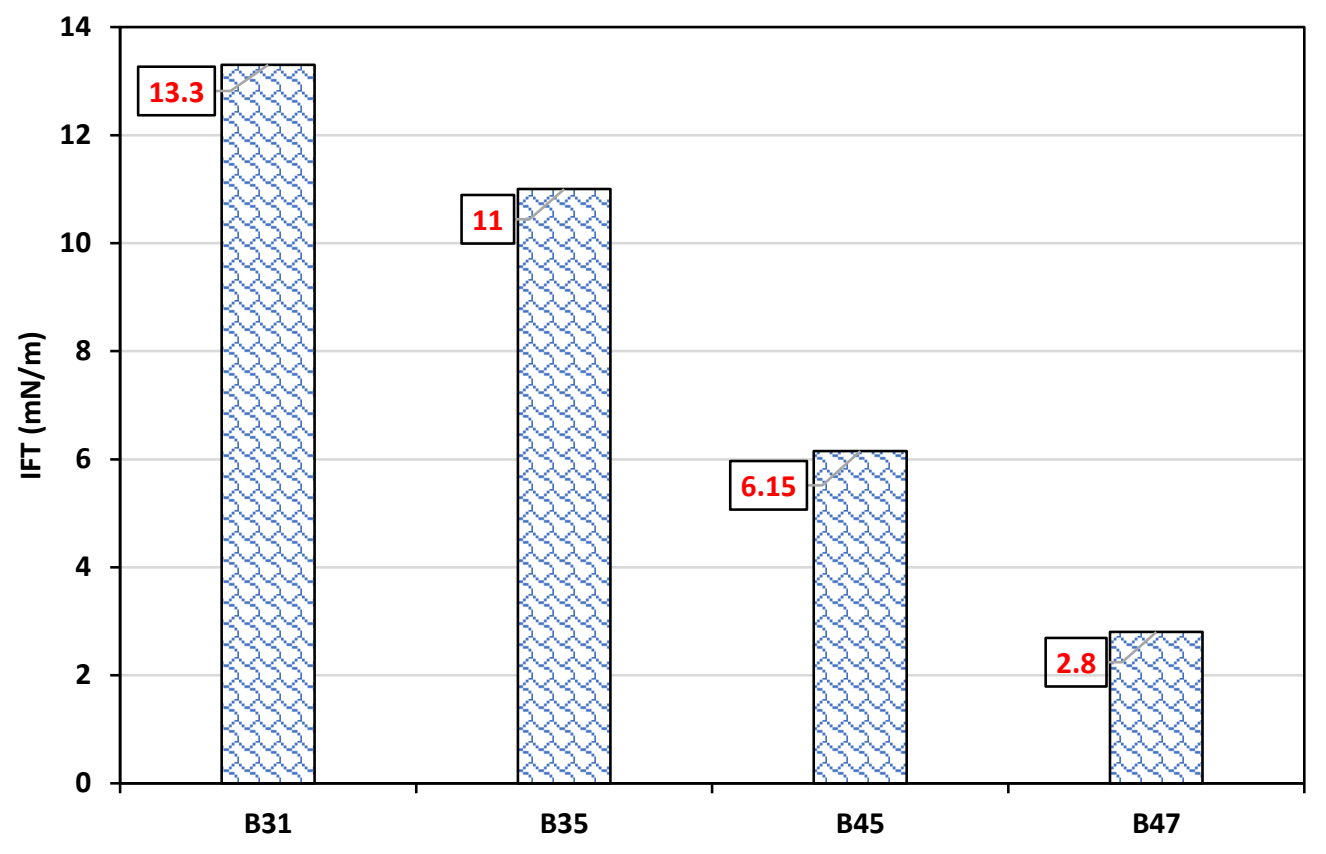

Fig. 9. Interfacial tension measurements for Cores B31, B35, B45, and B47. 
As can be noticed from all the tests carried out in this study, reservoir core 47, which were flooded with fifty times diluted seawater and foam, is showing the best results among other reservoir cores. The interfacial tension was the lowest among the other cores. The contact angle was the lowest too, before and after core flooding. Besides, the ultimate and improved oil recovery was the highest, which was $72.77 \%$ of the OOIP. The effect of salinity is playing a significant role in altering sandstone wettability towards being more water-wet, and it enhances the efficiency of foam as well. As the salinity decrease, interfacial and contact angle decreases too, and in turn, oil recovery increases.

\section{Conclusion}

Generally speaking, foams are used for gas mobility and water cut reduction. Injected gas such as $\mathrm{CO}_{2}$ and $\mathrm{N}_{2}$ is less viscous and dense that the in-situ crude oil and water. This led to gas channeling, overriding, and early breakthrough. However, foams were applied in this study to improve the mobility and sweep efficiency of the residual oil in the cores assisted by LS water. The surfactant used in foam stabilization prompted water-oil interfacial tension reduction. Reducing residual oil saturation prompted interfacial tension to decrease. LS water, on the other hand, triggered the sandstone wettability to be more water-wet, which increased oil recovery. As the salinity decreases, the oil recovery increases. This was determined by conducting water-flooding experiments on four cores. Performing another four experiments using foam and different brines revealed that the lower brine salinity, the higher the oil recovery. Combining LS water and foam flooding is an emerging EOR process that takes advantage of the relative strengths of both methods. The results of both contact angles and IFT were in line with core flooding results. 


\section{Acknowledgement}

The authors would like to express their appreciation to the Higher Committee for Education

Development in Iraq and the Iraqi Ministry of Oil/ Missan Oil Company for their support.

The authors would also like to express their appreciation to Colt Energy, Inc., especially

John Amerman for providing crude oil for this study.

\section{References}

Al-Saedi, Hasan. N., \& Flori, R. E., 2018f. Enhanced oil recovery of low salinity water flooding in sandstone and the role of clay. Petroleum Exploration and Development, 45(5), 927-931. https://doi.org/10.1016/s1876-3804(18)30096-x .

Al-Saedi, Hasan. N., Brady, P. V., Flori, R. E., \& Heidari, P., 2019b. Insights into the role of clays in low salinity water flooding in sand columns. Journal of Petroleum Science and Engineering, 174, 291-305. https://doi.org/10.1016/j.petrol.2018.11.031.

Al-Saedi, Hasan. N., Flori, R. E., \& Al-Jaberi, S. K., 2018e. Eliminate the role of clay in sandstone: EOR low salinity water flooding. Journal of Petroleum Exploration and Production Technology. https://doi.org/10.1007/s13202-018-0548-y.

Al-Saedi, Hasan. N., Flori, R. E., \& Brady, P. V., 2019a. Effect of divalent cations in formation water on wettability alteration during low salinity water flooding in sandstone reservoirs: Oil recovery analyses, surface reactivity tests, contact angle, and spontaneous imbibition experiments. Journal of Molecular Liquids, 275, 163-172.

Austad, T.; RezaeiDoust, A.; Puntervold, T., 2010. Chemical mechanism of low salinity water flooding in sandstone reservoirs. Proceedings of the 2010 Society of Petroleum Engineers (SPE) Improved Oil Recovery Symposium; Tulsa, OK; SPE Paper 129767.

Austad, T., 2013. Water-Based EOR in Carbonates and Sandstones. Enhanced Oil Recovery Field Case Studies, 301-335. https://doi.org/10.1016/b978-0-12-3865458.00013-0.

Awolayo, A. N., Sarma, H. K., \& Nghiem, L. X., 2018. Brine-Dependent Recovery Processes (Smart-Water/Low-Salinity-Water) in Carbonate and Sandstone Petroleum Reservoirs: Review of Laboratory-Field Studies, Interfacial Mechanisms and Modeling Attempts. https://doi.org/10.20944/preprints201810.0126.v1. 
Chevallier, E., Chabert, M., Gautier, S., Ghafram, H., Khaburi, S., \& Alkindi, A., 2018. Design of a Combined Foam EOR Process for a Naturally Fractured Reservoir. Society of Petroleum Engineers. https://doi.org/10.2118/190363-MS.

Craig, F.F., 1971. The Reservoir Engineering Aspects of Waterflooding, vol. 3, HL Doherty Memorial Fund of AIME, New York, NY, 45-47.

Denney, D., 2013. Foam-EOR Pilot: Mature Volatile-Oil Reservoir Under Miscible-Gas Injection. Society of Petroleum Engineers. https://doi.org/10.2118/0613-0117-JPT.

Dugstad, O., Opel, K., \& Fjelde, I., 2011. Improved understanding of $\mathrm{CO}_{2} /$ Foam EOR Techniques by aid of Tracer Technology. Society of Petroleum Engineers. https://doi.org/10.2118/142985-MS.

Guo, H., Faber, M. J., Buijse, M. A., \& Zitha, P. L. J., 2011. A Novel Alkaline-SurfactantFoam EOR Process. Society of Petroleum Engineers. https://doi.org/10.2118/145043MS.

Kamranfar, P., \& Jamialahmadi, M., 2014. Effect of surfactant micelle shape transition on the microemulsion viscosity and its application in enhanced oil recovery processes. Journal of Molecular Liquids, 286-291. https://doi.org/10.1016/j.molliq.2014.07.009.

Lee, S., \& Kam, S. I., 2015. MoC-Based Modeling and Simulation of Foam EOR Processes in Multi-Layered System. Offshore Technology Conference. https://doi.org/10.4043/25716-MS.

Mast, R. F., 1972. Microscopic Behavior of Foam in Porous Media. Society of Petroleum Engineers. https://doi.org/10.2118/3997-MS.

Nasralla RA, Nasr-El-Din HA. 2014. Impact of cation type and concentration in injected brine on oil recovery in sandstone reservoirs. J Petrol Sci Eng; 122:384-95.

Ocampo, A., Restrepo, A., Cifuentes, H., Hester, J., Orozco, N., Gil, C., Gonzalez, C., 2013. Successful Foam EOR Pilot in a Mature Volatile Oil Reservoir under Miscible Gas Injection. International Petroleum Technology Conference. https://doi.org/10.2523/IPTC-16984-MS.

Schramm, L. L., 2010. Surfactants: Fundamentals and Applications in the Petroleum Industry. Cambridge, England: Cambridge University Press.

Skauge, A., Aarra, M. G., Surguchev, L., Martinsen, H. A., \& Rasmussen, L., 2002. FoamAssisted WAG: Experience from the Snorre Field. Society of Petroleum Engineers. https://doi.org/10.2118/75157-MS.

Svorstol, I., Vassenden, F., \& Mannhardt, K., 1996. Laboratory Studies for Design of a Foam Pilot in the Snorre Field. Society of Petroleum Engineers. https://doi.org/10.2118/35400-MS. 
Tang, G. Q., \& Morrow, N. R., 1997. Salinity, Temperature, Oil Composition, and Oil Recovery by Waterflooding. Society of Petroleum Engineers. https://doi.org/10.2118/36680-PA.

Xie, Q., Liu, F., Chen, Y., Yang, H., Saeedi, A., \& Hossain, M. M., 2019. Effect of electrical double layer and ion exchange on low salinity EOR in a pH controlled system. Journal of Petroleum Science and Engineering, 174, 418-424. https://doi.org/10.1016/j.petrol.2018.11.050. 